\title{
Problems and Solutions of Stakeholder Coordination Mechanisms for Chinese Modern Agriculture at Present
}

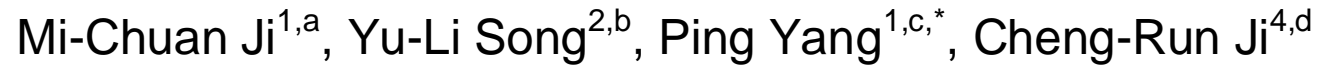 \\ ${ }^{1}$ Shandong Institute of Agriculture Sustainable Development, Shandong, Jinan, 250100, China \\ ${ }^{2}$ Shandong Rural Science and Technology Promotion Center, Shandong, Jinan, 250010, China \\ ${ }^{3}$ Shandong Agricultural Finacing Guarantee Co., Ltd, Shandong, Jinan, 250014, China \\ ajmc6668@163.com, bxhbsyl@163.com, cpingivy@163.com, ${ }^{\text {dj }}$ jarrycheng@foxmail.com \\ ${ }^{*}$ Corresponding author
}

Keywords: Modern agriculture, Stakeholders, Coordination mechanism, Problems and solutions.

\begin{abstract}
This paper focuses on analyzing the outstanding problems and contradictions between benefit main bodies of Chinese modern agriculture from the angle of new four modernizations synchronization strategy based on the field investigation data, including agricultural enterprises and farmers, agricultural enterprises and government, research institutions, the farmers and research institutions of scientific. In addition, the role positioning of each stakeholder and modern agriculture construction of benefit mechanism was overall planned from the strategic height of the new agricultural modernization development.
\end{abstract}

\section{Introduction}

The grand picture of new "four modernizations" synchronization strategy, which will guide China's future development, was put forward in the CPC's eighteenth conference. The unique new agriculture modernization is an important foundation of the new industrialization and new urbanization. At the same time, the new agriculture modernization, the new industrialization and new urbanization are converged, undivided and promoted with each others, and do not contend for resources.

Because of the requirements cultivating new business entities and promoting unique New Agriculture Modernization, it is necessary for us to analyze and consider the stakeholders of modern agriculture and the coordination mechanism, to build perfect collaborative framework, straighten out the problems of coordination of interests among the stakeholders in modern agriculture's development, and promote the sustained and healthy development of modern agriculture in our country. [1] This is the urgent problems need to be solved in promoting the modern agriculture under the framework of new "four modernizations".

\section{Outstanding problems and contradictions among the stakeholders in current modern agriculture}

According to the survey in recent years, we find that some new contradictions and conflicts among the stakeholders have emerged in construction of promoting the modern agriculture under the sync framework of new "four modernizations", and this will hinder the sustained and healthy development of modern agriculture. [2] Table 1 shows a statistical result about cooperation satisfaction for various stakeholders.

Tab.1 Statistics of various stakeholders' cooperation satisfaction

\begin{tabular}{cccccccc}
\hline series & $\begin{array}{c}\text { Very } \\
\text { satisfy }\end{array}$ & Satisfy & $\begin{array}{c}\text { Just } \\
\text { so so }\end{array}$ & $\begin{array}{c}\text { Not } \\
\text { satisfy }\end{array}$ & $\begin{array}{c}\text { Very } \\
\text { not } \\
\text { satisfy }\end{array}$ & $\begin{array}{c}\text { total } \\
\text { number }\end{array}$ & $\begin{array}{c}\text { Weighted } \\
\text { average }\end{array}$ \\
enterprises & 1 & 16 & 13 & 2 & 0 & 35 & 3.37 \\
farmers & 1 & 13 & 20 & 5 & 0 & 38 & 3.29 \\
government & 5 & 18 & 10 & 4 & 0 & 34 & 3.79 \\
research & 2 & 18 & 13 & 1 & 0 & 35 & 3.57 \\
institution & 2 & & & & & &
\end{tabular}


These kinds of contradictions and conflicts among the stakeholders can be classified as follows:

\section{Agriculture-related enterprises and farmers}

(1) Farmer's cannot overcome the financing difficulties. The outstanding difficulty for them is credit, because they cannot find the guarantor or guarantee organization, and the guarantee procedures are too complex for them.

(2) They are unwilling to invest in technological innovation and product upgrading.

(3) The benefit-sharing mechanism and the inconsistency of interest constitute a contradiction. This problem is mainly manifested in two aspects as follows:

First, opportunism behavior makes the leading enterprise and farmers stand in relatively opposite interest state, and the leading enterprises and farmers' pursuing their own maximum interest results in the behavior. Second, there exists the contradiction that the risk is easy to pass on.

(4) The information asymmetry between companies and farmers usually leads to game. Between companies and farmers, farmers are often passive to accept leading enterprises' contract arrangement, but the leading enterprises may minimize the farmers' pay until merely meet their demand for reservation utility, in order to ensure its own maximum profit.

(5) Because of low intermediary costs and organizational problems, the agricultural intermediary organizations are in trouble.

(6) Agriculture-related enterprises' investment and cost to the control of products quality is too high, and the capital return is low, while the expenditures to farmers are rigid. At the same time, the market's inflation cut the profits of both sides.

\section{Agriculture-related enterprises and government}

First, the government's support to common technology is not enough. The government often tends to take matchmaker way, matching the research institutions and enterprises together but not putting the early start-up capital, which makes the common technology difficult to perform. Second, in the assessment, the government requires enterprises to promote farmers, which has the social benefit goal, and is common in the evaluation of agricultural industrialization project, and this often leads to the contradiction of government target and enterprise benefit. Third, the contradiction is relatively greater on the use of land resources between government and enterprises, especially the contradiction between enterprise circulation land, changing the original agriculture purposes and developing efficiency priority industry, with government basic farmland, having other functions. At the same time, the conflicts that go against to the government's green safety planning goal cannot be neglected, such as the pollution control measures can't keep up with the development of aquaculture with area source pollution. Fourth, the government agricultural subsidies tend to farmers instead of enterprises, while the enterprises wants the government to subsidized by agricultural products, and the subsidies standards should be mainly based on the output of products, but not early farmers behavior.

\section{Agriculture-related enterprises and research institutions}

In the view of overall cooperation between the agriculture-related enterprises and research institutions, the development situation is good, but there are still contradictions between two sides, mainly concentrated in the aspect of resource sharing. The equipments of research institutions and universities are purchased by state funding, and information platform is rich, thus enterprises want to share more in this aspect, but the lack of sharing mechanism form an obstacle at present.

In addition, agricultural enterprises and research institutions focus on different points, the scientific research colleges and universities mainly focus on basic and frontier research, which is easier to acquire achievements, this is the main assessment indicators and main assessment basis of promotion in scientific research institutions. While the enterprises pay more attention to practical application of the scientific research achievements, thus the gap between the two is big. 


\section{Government and research institutions}

Research project emphasis on innovative research and basic research, and the efforts to support applied research is not enough. Too much attention is attached to the quality and quantity of the article in the research evaluation system and the transformation of scientific and technological achievements share with less attention. The papers are still given priority in the assessment and evaluation of applied results is relatively weak. So the innovation system mainly constructed by enterprises still faces the multi-level and multi-objective transformation in guidance, device, fund, application, and evaluation etc.

\section{Research institutions and farmers}

Research institutions and farmers hardly communicate with each other directly, so farmers ask enterprise's technical department for help at first, in the face of difficult technical problems. The principal contradiction is that farmers are limited by the education and knowledge level when accept new technology.

\section{Two Strategies}

\section{In the view of the stakeholders of New Agriculture Modernization overall planning at strategy level}

Aiming at the current problems and conflicts of stakeholders in the development of modern agriculture, in order to maintain the sustained and healthy development of modern agriculture, we should make unified planning and assign roles for the stakeholders of New Agriculture Modernization at the strategic height of New Agriculture Modernization development, according to the strategic requirements of "new four modernizations" put forward in the CPC's eighteenth conference.

(1) The new business entities of agriculture-related enterprises and modern agriculture

Agriculture-related enterprises are not only the new agricultural business entities but the stakeholders, in the development of modern agriculture, thus they should be the leading enterprises promoting modern agriculture. They are the market pioneers promoting modern agriculture, and impellers of the construction of modern agricultural industrial chain. According to the integration model and mechanisms that the government set up the market, the market leads the faucet, the faucet drives the base, and the base connects farmers, We should drive agriculture to base construction, scale development, industrialization, mechanization, standardization production, and green production, so as to accelerate the construction of characteristic New Agriculture Modernization. And agriculture-related enterprises should recognize their commitment to regional economic development from a strategic height, take the strategic role of new subject in modern agriculture development, and expand their own strength gradually. And only by this, can they realize their own vision, which can be full proven by the practice of agricultural industrialization in our country.

(2) The farmers (farmers, including large planting and breeding farmers -modern agricultural professional producers or modern farm managers.

As one of the most basic agricultural production decision unit, the famer who bases on consanguinity is engaged in agricultural production and operation activities. The farmer is a functional unified unit of society and economy. In the process of propelling the new type of agricultural modernization, farmers should speed up the change from traditional agricultural production and operation subject to new professional producer or the role of modern family farm managers, which is determined by the factors of production characteristics of agriculture itself. Agricultural production and management cannot leave the farmer (the most basic unit). But it should be clear, in the development of modern agriculture farmers are different from those of traditional agriculture, they must abandon small-scale farming operation. Farmers need to change 
their identities into modern professional producers or managers in the agricultural industry, and it is the development orientation of transformation. As a result, they must accelerate role conversion.

(3) The innovation of the modern agricultural scientific research institutions - resource and technology support.

According to the role orientation of promoting agricultural modernization, research institutions should make strategic and appropriate adjustment, and focus on playing the role of innovation resource library and technology support body. This innovation resource library contains two meanings. The first is the agricultural scientific research institutions should reserve enough knowledge of agricultural science and technology, in response to the changing enterprise technology development requirements. Second, the agricultural research institutions including university should be the base of keeping and training scientific and technical personnel, and can provide and output high-quality scientific and technical workers to agricultural enterprise at any time. They should also be the strong supporters and actors in enterprise innovation activities. In this case, the technology support body mainly provides intellectual support of science and technology in transforming the farmers' identities into modern vocational famers or modern farm managers.

(4) The referee and waiter of government - modern agricultural

Government gives agricultural development supports, guides, coordination, rules and services mainly through the provision of system and environment, and moderates macro-control makes efforts to create an environment of fair competition. In the process of propelling the new type of agricultural modernization, there are two reasons why defining government as the referee and waiter. On the one hand, the government should reduce directly involving in the entity management and the intervention of market, focusing on policy guidance and planning. On the other hand, being a good waiter is the inherent requirement of building a service-oriented government. The government should focus on enterprise development and improvement of the livelihood of the people, and actively create a negotiation, cooperation and common development platform for each benefit body, promoting social harmony and progress.

\section{Optimize the interest mechanism of related bodies on the level of new agricultural modernization management}

According to the new strategic deployment and requirement of agricultural modernization, in order to promote the development of modern agriculture, we must solve the modern agriculture coordinated development mechanism of various stakeholders. So, we should first clear the interests of the relationship between modern agriculture each related subject, find the convergences and differences, optimize the mechanism of interest at the same time, prevent the wrong priorities and functional dislocation, and give full play to the initiative of promoting the interest subjects..

Strengthen the convergence mechanism of the interest of the subject

In the new type of agricultural modernization in the process, the government, agricultural enterprises, scientific research institution, farmers and other rele vant stakeholders are in the same system, working together and promoting each other. Among them, agricultural enterprises and farmers are both the main bodies of market economy and modern agriculture, and the pursuit of profit maximization is the biggest motivation of the development of agricultural. Science and technology innovation support of scientific research institutions and guidance and support of the government's, etc., are the assistant power of modern agricultural development.

From the new direction of agricultural modernization, Commercialization, market, industry, technology, green technology, mechanization and intelligence are the main symbols of modern agriculture. But from the reality of our country agriculture, decentralized management, the contradiction between the small farmers and big market, and so on, will hinder the development process of the modern agriculture.

Developing leading enterprises as the main body of modern agriculture, extending the prenatal, during production, postnatal chain of agricultural products, and promoting agricultural industrialization is one of the effective ways to solve the contradictions. It can make the farmers, leading enterprises, as well as scientific research institutions and relevant stakeholders willing to 
regard contracts or assets as ties, forming a community of interests. This is the driving force of modern agricultural production and operation. At the same time, according with the government's target of agricultural development, the government will give guide, support, coordination, rules and service, proper macro regulation and control to optimize the allocation of resources elements combination and interest adjustment. The establishing and perfecting of the government's system innovation and the behavior mechanism can create good external conditions for modern agriculture.

The mechanism of each related interest subjects convergence in promoting new agricultural modernization should be strengthened in the future. The government should make manpower planning and layout and the policy support, promote a good and fast development of modern agriculture.

Set up and perfect the interests of coordination mechanism.

During modern agricultural development, there are both convergence and no convergence of interests of various related subjects, thus forming the interaction and gaming among the interests of the subject. Such as farmers hope to share the modern agriculture to bring more benefits, enterprises require further unfettered, especially gaining greater space in the property rights of land and funding sources, while the government's goal is to further increase the local fiscal revenue, to drive people out of poverty to become rich as much as possible and so on. The essence of the conflict is differentiation and update of resources allocation of the demands. All parties want to make their own resources quantity and continue to optimize the structure, so in practice they show remarkable skills, and adopt a series of organizational changes to strive for the share of bigger cake. Such as agricultural enterprises begin to create material base and absorb the farmers into the company's operations within the workshop in order to obtain high quality raw materials and reduce the cost, farmers increase its bargaining position and ability to resist the market risk through the form of cooperation economic organization, etc. This kind of game often cause contradictions between the interest subjects, and have certain barrier effect on modern agricultural development. Thus, we need to optimize and choose the suitable Chinese cooperative mechanism in accordance with the requirements for the overall deployment of modern agricultural development and according to the game of different interest subjects. There are three key construction mechanisms: first is the strategic guidance mechanism, second is the benefit coupling mechanism, third is technology support mechanism. Each benefit main body should be in three mechanisms under the guidance, regard interest as the tie, form a community of interests, construct the interests of the subject of building collaborative optimization mechanism, and promote the development of modern agriculture.

Improve stakeholders' coordination level [3]

Each benefit main body coordination mechanism construction from the pragmatic levels should highlight the following points. Fig 1 shows the relationships between various stakeholders.

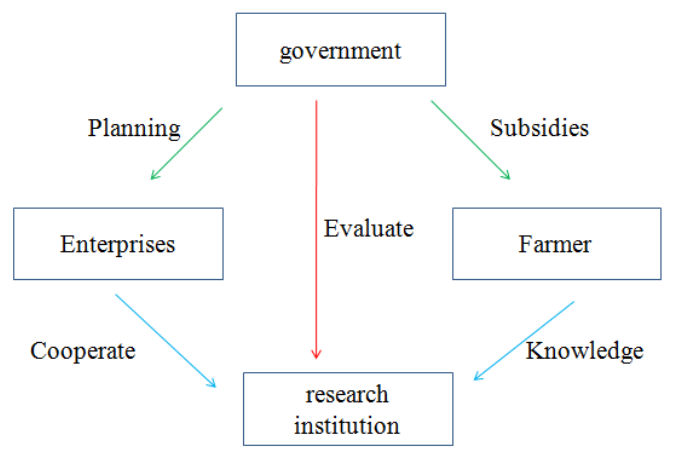

Fig.1 The relationship between each stakeholder

(1)Agricultural enterprises: First, they should combine the vision of enterprise development goals and leading the regional modern agriculture development goal responsibility into an organic whole, overall planning and layout. Second, they should strengthen the agricultural leading enterprises' 
driving function. It mainly reflects in extending the industrial chain, leading agriculture to enter the modernization orbit. It mainly manifested in "four imports and two outputs". "Four imports", namely the import market, achieve order village and household.

(2)Government: The macro-control should be strengthened. The emphasis is as follow: firstly, more financial support should be gradually shifted to farmers by the quantity and quality of output subsidies from farmers planting subsidies. At the same time, government should build technical common bridges and promote the level of cooperation and efficiency of enterprises and research institutes; secondly, it should improve research conditions of scientific research institutions and further strengthen the guidance, support for agricultural application research, and speed up the transformation of scientific research achievements, which finally speed up the raise the level of modern agricultural science and technology. Thirdly, government should adopt the mode of policy and funding support to promote the industrialization linked by construction companies, farmers and scientific research institutions.

(3) Scientific research institutions: They should take the initiative to cooperate with agricultural enterprises and farmers to form a win-win situation.

(4)Farmers: They should gradually improve the credit consciousness and the level of technology and production management when contacts with agricultural enterprises, local governments, research institutions to become the new professional farmers or modern farm managers.

\section{References}

[1] Zhang Fuping, Wang Xin, Wang Bo, Zhou Nan. Research on Synergetic Mechanism of Interest Stakeholders in China's Urban Modern Agriculture Industry, Technology Management Research ,34(302).1-5,2014.

[2] Lu Liang Shu. Chinese Agriculture Development and Modern Agriculture Building in New Period, China Engineering Science, 6(1): 25-26, 2004.

[3] Ji Ming-chuan, A new path of agricultural modernization research in Shandong province China, Agricultural Science Press: Beijing, pp. 71-74, 2011. 